\title{
Viscoelastic Properties of the Rectal Wall in
}

\section{Hirschsprung's Disease}

\author{
Pierre Arhan, Ghislain Devroede, Ken Danis, Catherine Dornic, \\ Claude Faverdin, Bernard Persoz, and Denys Pellerin, Départements de \\ Physiologie et de Chirurgie Pédiatrique, Faculté de Médecine Necker, \\ Université Paris V, Paris, France, et Unité de Recherche Gastrointestinale, \\ Université de Sherbrooke, Sherbrooke, Québec, Canada
}

\begin{abstract}
A B S TRACT Viscoelastic properties of the rectal wall were compared in 30 normal children and in 28 children with Hirschsprung's disease. The elasticity of the rectal wall after accomodation to distension was found to be significantly greater $(P<0.001)$ in patients, and the time taken by the rectum to accomodate was also found to be longer $(P<0.001)$. The increased elasticity correlated well with severity of the illness, but none of the parameters correlated with length of aganglionic segment. Measuring elastic properties of the rectal wall may help to assess the severity of illness in patients with Hirschsprung's disease.
\end{abstract}

\section{INTRODUCTION}

In its usual form, Hirschsprung's disease is characterized by an aganglionic rectosigmoidal segment with inefficient motility, proximal to which the colon is dilated $(1,2)$. The severity of clinical symptoms does not always reflect the length of aganglionic segment. In our experience, $73 \%$ of 75 patients seen before 2 mo of age and suffering from Hirschsprung's disease could be treated for more than 9 mo by colonic irrigation through a rectal catheter up to the time of definitive surgery. The remaining $27 \%$ had to undergo a colostomy because they remained in poor general conditions and suffered from enterocolitis. In the first group, aganglionosis involved the rectum, rectosigmoid, and left colon in 65, 32, and $3 \%$ of the cases, respectively. In the second group, it involved these same segments in 20,35 , and $45 \%$, respectively. ${ }^{1}$ Thus, although there was a statistical correlation between length of aganglionic segment and need for an early colostomy, patients with a short aganglionic segment could run a poor clinical course. Conversely, patients with agangliono-

Received for publication 13 April 1977 and in revised form 23 February 1978.

${ }^{1}$ Unpublished observations. sis of the entire large bowel may reach adulthood without serious complications (3).

The resistance of the aganglionic area depends not only upon its length and lack of efficient propulsion but also on its ability to expand. In a previous study (4), viscoelastic properties of the rectal wall were quantitatively studied by a noninvasive technique and modelized rheologically by an elastic element in parallel with two viscoelastic ones, i.e., two viscous parameters and three elastic ones. The purpose of the present study was to compare analytically the rheological behavior of the rectal wall of normal subjects and patients with Hirschsprung's disease. This was done by distending the rectum and testing each parameter of the model. A pathophysiologic counterpart to severity of disease, resistance to distension, has been found and may have a prognostic value in Hirschsprung's disease.

\section{METHODS}

30 subjects (aged 5 mo to $14 \mathrm{yr}$ ) were compared to 28 patients (aged $1 \mathrm{mo}$ to $14 \mathrm{yr}$ ) with Hirschsprung's disease. The control subjects were hospitalized for the repair of congenital malformations unrelated to the gastrointestinal tract. They had normal bowel habits and no anorectal abnormalities. They were studied either before surgery or the day of dismissal In patients with Hirschsprung's disease, the diagnostic was proven both by an absence of neurones at histological postoperative evaluation of the distal bowel and the absence of a rectoanal inhibitory reflex $(5,6)$. The subjects were investigated recumbent in the morning. Some were sedated because of restlessness (diazepam $0.15 \mathrm{mg} / \mathrm{kg}$ IM or hydroxysine dichlorhydrate per os $1 \mathrm{mg} / \mathrm{kg}$ ). This did not influence the validity of results $(7,8)$.

The parameters of elasticity and viscosity were measured with a four-channel probe (Etablissements Marquat-Paris) (Fig. 1). It was made of a soft polyethylene tube (outside diameter $=8 \mathrm{~mm}$ ) containing four parallel channels (inside diameter $=0.8 \mathrm{~mm}$ ). Two of these were connected to a balloon fixed to the extremity of the probe and used for rectal distension. This balloon remained spherical, whatever the distending volume between 5 and $50 \mathrm{ml}(4)$. The other extremity of the first channel was connected to a syringe to inject air, 


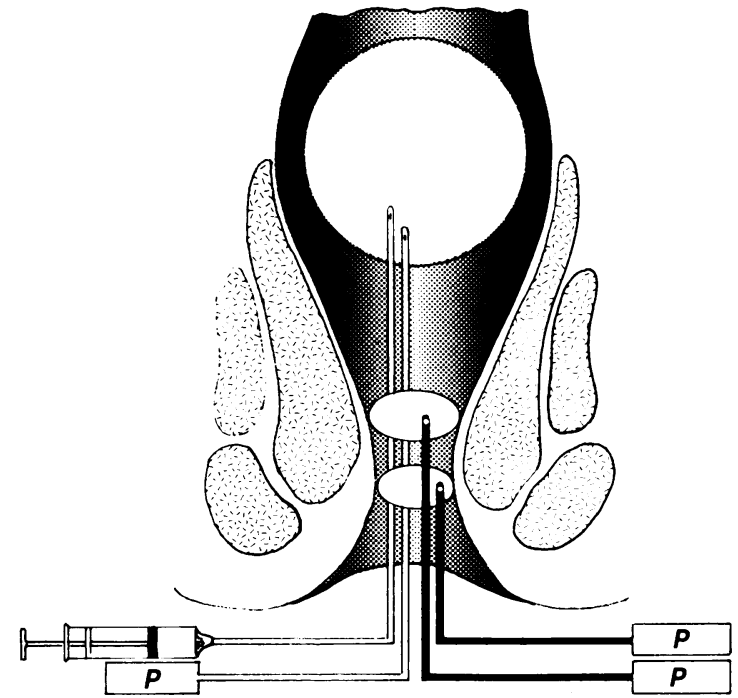

Figure 1 Probe used to study viscoelastic properties of the rectal wall. Pressures are recorded in an air-filled, rectal balloon while it is distended and in two smaller, water-filled, anal balloons.

and that of the second one to a pressure transducer (PM 6, Statham Instruments, Inc., Oxnard, Calif.) and amplifier (1008, Statham). Measuring the pressure directly inside the inflating balloon, rather than through a side-arm connected to the syringe, avoided high-pressure artifacts during air injection. $4 \mathrm{~cm}$ below the distending balloon, there were two smaller, ring-shaped, and water-filled balloons, sized $13 \mathrm{~mm}$ (diam) $\times 9 \mathrm{~mm}(\mathrm{ht})$, and separated from each other by $9 \mathrm{~mm}$. They were connected through the last two channels of two pressure transducers (PM 6, Statham) and amplifiers (1008, Statham). These balloons served a double purpose of locating the probe in standard conditions and confirming the absence of a rectoanal inhibitory reflex in Hirschsprung's disease. The probe was inserted into the anal canal so that the lowermost balloon was barely visible at the anal margin. Data were recorded graphically (SP 2000, Statham).

The rectal balloon was inflated in less than $0.1 \mathrm{~s}$ in a random order with $10,20,30,40$, and $50 \mathrm{ml}$ of air measured in the syringe, at room temperature and pressure. By injecting air rather than water it was possible to distend the balloon more rapidly, but the volume of air present in the distended balloon was smaller than the actual volume present in the syringe before injection because of latex resistance to stretch. The actual volume in the balloon corresponding to the amount of air injected was measured in in vitro experiments by determining the amount of water displaced in a graduated cylinder with the balloon immersed in water. The injections of air in the rectal balloon were separated by 2 -min intervals and maintained for $1 \mathrm{~min}$ until the balloon pressure was stabilized. The balloon was then deflated. In a previous study, the reproducibility of results was established in similar conditions in five normal subjects (4). After each experiment, the pressure in the distending balloon was also measured in the air above some water at $37^{\circ} \mathrm{C}$ in a flask, with the same volumes used to distend the rectum. This was done in strict conditions because of the wide variability of latex performance according to humidity and temperature. Finally, the in vitro pressure values were subtracted from the in vivo values to abolish the effects of extraneous compliances in the system.
Treatment of data. The recorded pressure in the rectum during continuous distension appears as a decreasing function of time up to an asymptotic value. In some cases a secondary peak was superimposed on the curve. Graphical analysis of the curves on a semilogarithmic paper demonstrated that they were the sum of two exponential functions, an asymptotic value and an added reactive peak (4). A mathematical translation of this phenomenon is:

$$
p=p_{x}+p_{\mathrm{A}} \mathrm{e}^{-a t}+p_{\mathrm{B}} \mathrm{e}^{-b t}+F(p),
$$

where $p=$ the pressure at a given time, $p_{x}=$ the asymptotic value of the pressure, and $p_{\mathrm{A}}$ and $p_{\mathrm{B}}=$ the ordinates of each exponential curve at time zero; $a$ and $b=$ the inverse value of the time constants and $F(p)=$ the reactive inconstant peak.

From the pressure values, the superficial tension of the surrounding rectal wall may be calculated by applying Laplace's law:

$$
\mathrm{T}=981 \frac{p r}{2},
$$

where $p=$ pressure $\left(\mathrm{cm} \mathrm{H}_{2} \mathrm{O}\right)$ and $r$ = radius of the distending balloon $(\mathrm{cm})$. Thus three corresponding tension values were obtained:

$$
\mathrm{T}_{x}, \mathrm{~T}_{\mathrm{A}} \text {, and } \mathrm{T}_{\mathrm{B}} \text {. }
$$

In a previous study in normal subjects (4), a linear relationship was demonstrated between the neperian logarithm of the wall tension $T_{\infty}, T_{A}$, and $T_{B}$ and the radius of the balloon. For each subject in this study the regression line of the same logarithmic values of the wall tensions was also calculated in function of the radius of the distending balloon. General expression of each regression line may be:

$$
\ln \mathrm{T}=\alpha \mathrm{r}+\beta,
$$

where $\ln T=$ the neperian logarithm of rectal wall tension, $\alpha=$ the slope of the regression line, $\beta=$ the ordinate at origin of the same line, and $r=$ the radius of rectal balloon.

For each value $\mathrm{T}_{x}, \mathrm{~T}_{\mathrm{A}}$, and $\mathrm{T}_{\mathrm{B}}, \alpha$ becomes the elastic coefficients $E_{\infty}, E_{A}$, and $E_{B}$ of the rectal wall. Its value is obtained by determining the slope of each regression line.

There is no correlation between the value of the time constants $1 / a$ and $1 / b$ and the radius of the balloon (4). In this study, individual values of $a$ and $b$ were determined by calculating the mean values of $a$ and $b$ obtained in each subject for each distension.

Illness severity was evaluated in each patient by attributing a score of 1 or 0 to the presence or absence of five clinical features: $(a)$ being less than 2 mo of age, $(b)$ neonatal obstruction, $(c)$ enterocolitis (with or without perforation), $(d)$ inefficiency to prevent obstruction of repeated rectal irrigations up to the time of surgical treatment, and $(e)$ need for a colostomy because of a poor clinical course. A "severity index" between 0 and 5 was obtained by adding these values in each patient. The length of aganglionic area was evaluated by measuring the distance between the anal margin and the lower limit of the dilated colon at barium enema. It was subsequently controlled by histologic evaluation. This was done to determine whether the balloon was in an aganglionic zone or a normal area. A score of 1 was given when the balloon was in the aganglionic area, and of 0 when it was not.

Patients with Hirschsprung's disease were compared to controls by Mann and Whitney or Wilcoxon distribution-free tests and with Spearman's correlation coefficient (9). Data obtained in patients where the rectal distending balloon was above the aganglionic zone were compared by the same test to those where it was within this zone. 

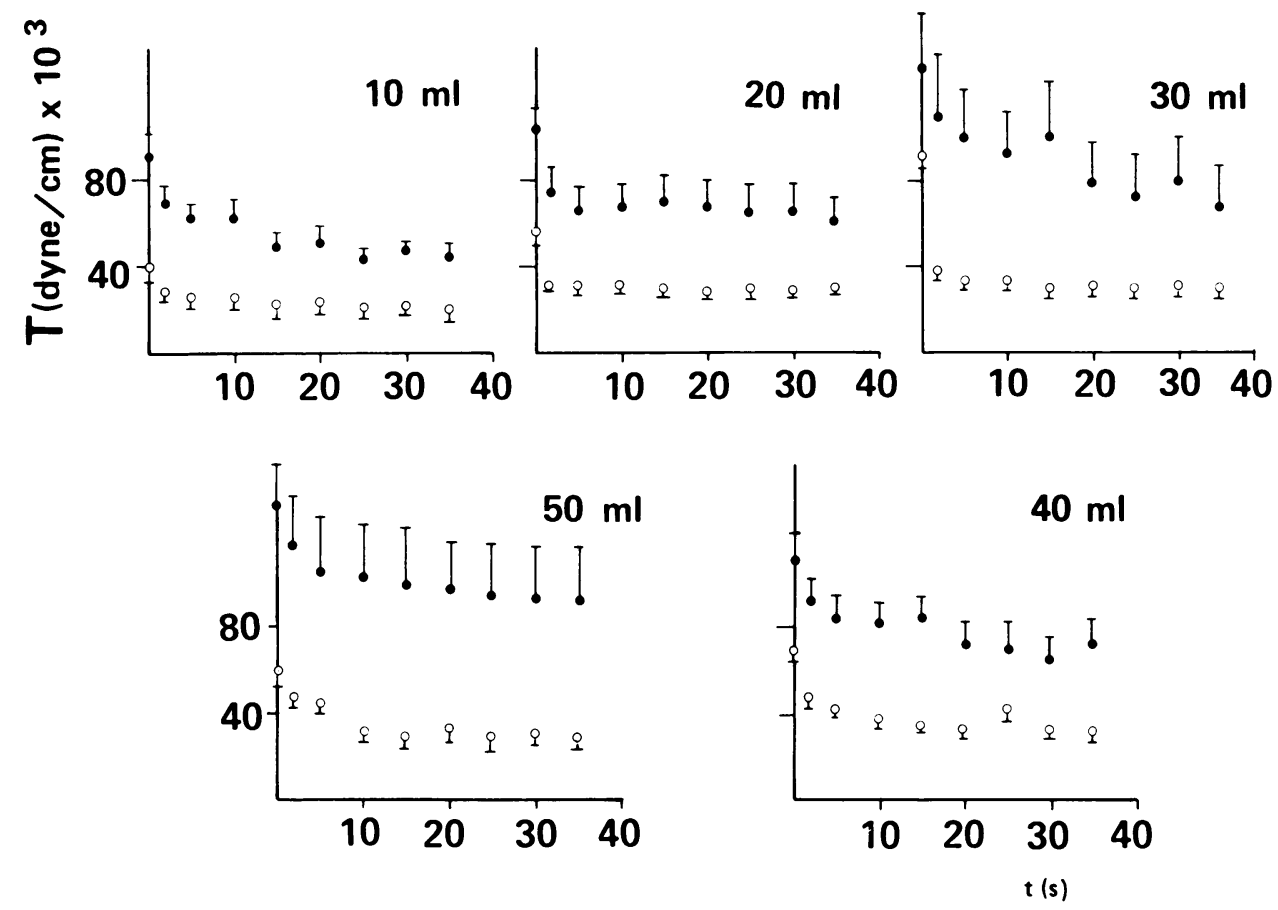

FIGURE 2 Rectal wall tension during maintained distension at different volumes (Mean $\pm \mathrm{SE}$ ). Accomodation of rectal pressure to sudden and maintained rectal distension in normal children and in patients with Hirschsprung's disease.

\section{RESULTS}

Fig. 2 shows the mean values of parietal tensions recorded in the rectum of normal children and of patients with Hirschsprung's disease during sudden maintained distension. Values shown were obtained after subtracting latex inflating pressure in the air as described above. These results show that the asymptotic values of the exponential curves are higher in the patients and that the decay time is longer in comparison with the normal subjects. Fig. 3 shows the relationship between wall superficial tension in health and disease, and balloon radius. Table I shows quantitative results of clinical and viscoelastic parameters obtained in patients with Hirschsprung's disease, and Table II shows a comparison of the viscoelastic parameters with normal subjects. In patients, the $E_{\infty}$ elastic modulus was significantly above normal. The other elastic moduli, $E_{A}$ and $E_{B}$, were not significantly different from normal. The time constants of the rectal wall relaxation were longer in patients with Hirschsprung's disease than in normal subjects.

The modulus $\mathrm{E}_{\infty}$ correlated $(r=0.67)$ significantly $(P<0.001)$ with the severity of clinical course in Hirschsprung's disease. The moduli $\mathrm{E}_{\mathrm{A}}(r=0.19)$,

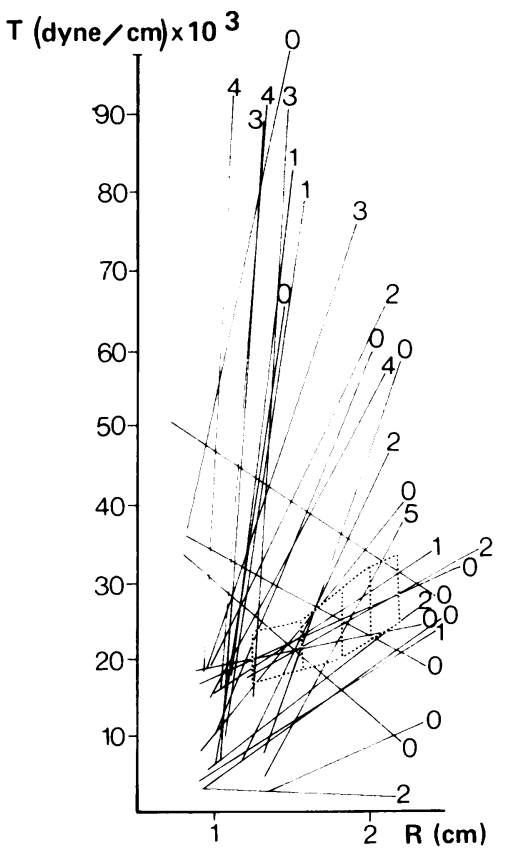

Figure 3 Tension-radius $\left(\mathrm{T}_{\infty}-r\right)$ relationship for controls and Hirschsprung patients. Illness severity is at the end of the lines. Normal range is in dotted lines. 
TABLE I

Relationship between Clinical Course of Hirschsprung's Disease and Viscoelastic Properties of the Rectal Wall

\begin{tabular}{|c|c|c|c|c|c|c|c|c|c|c|c|c|}
\hline \multirow{3}{*}{$\begin{array}{c}\text { Pa- } \\
\text { tients }\end{array}$} & \multirow{3}{*}{$\begin{array}{l}\text { Age } \\
<2 \\
\text { mo }\end{array}$} & \multicolumn{5}{|c|}{ Clinical parameters $(1=$ Present, $0=$ Absent $)$} & \multirow{3}{*}{$\begin{array}{c}\begin{array}{c}\text { Experimental } \\
\text { conditions }\end{array} \\
\text { Balloon in the } \\
\text { aganglionic area } \\
\text { (1 = present, } \\
0=\text { absent })\end{array}$} & \multirow{2}{*}{\multicolumn{5}{|c|}{ Elastic and viscous parameters of rectum }} \\
\hline & & \multirow{2}{*}{$\begin{array}{l}\text { Occlu- } \\
\text { sion }\end{array}$} & \multirow{2}{*}{$\begin{array}{c}\text { Entero- } \\
\text { colitis } \\
\text { or per- } \\
\text { foration }\end{array}$} & \multirow{2}{*}{$\begin{array}{l}\text { Ineffi- } \\
\text { cacity of } \\
\text { nursing }\end{array}$} & \multirow{2}{*}{$\begin{array}{l}\text { Colos- } \\
\text { tomy }\end{array}$} & \multirow{2}{*}{$\begin{array}{l}\text { Severity } \\
\text { index } \\
\text { (sum of } \\
\text { scores) }\end{array}$} & & & & & & \\
\hline & & & & & & & & $\mathrm{E} x$ & $\mathrm{E}_{\mathrm{A}}$ & $\mathrm{E}_{\mathrm{B}}$ & $\mathrm{a} / \mathrm{s}$ & $b / s$ \\
\hline & & & & & & & & dyne $\cdot \mathrm{cm}^{-2}$ & dyne $\cdot \mathrm{cm}^{-2}$ & $d y n c \cdot \mathrm{cm}^{-2}$ & & \\
\hline 1 & 1 & 1 & 1 & 1 & 1 & 5 & 1 & $38 \cdot 10^{4}$ & $16 \cdot 10^{4}$ & $48.5 \cdot 10^{4}$ & 0.03 & 0.26 \\
\hline 2 & 0 & 1 & 1 & 1 & 1 & 4 & 1 & $37 \cdot 10^{4}$ & & & & \\
\hline 3 & 0 & 1 & 1 & 1 & 1 & 4 & 1 & $33 \cdot 10^{4}$ & $4.3 \cdot 10^{4}$ & $-5.3 \cdot 10^{4}$ & 0.17 & 1.29 \\
\hline 4 & 0 & 1 & 1 & 1 & 1 & 4 & 1 & $3.8 \cdot 10^{4}$ & $0.22 \cdot 10^{4}$ & $0.49 \cdot 10^{4}$ & 0.09 & 0.76 \\
\hline 5 & 1 & 0 & 1 & 1 & 0 & 3 & 0 & $32 \cdot 10^{4}$ & $-0.55 \cdot 10^{4}$ & $-0.3 \cdot 10^{4}$ & 0.14 & 0.66 \\
\hline 6 & 1 & 0 & 1 & 1 & 0 & 3 & 1 & $30 \cdot 10^{4}$ & & & & \\
\hline 7 & 1 & 1 & 1 & 0 & 0 & 3 & 0 & $6 \cdot 10^{4}$ & $-2.9 \cdot 10^{4}$ & $1.2 \cdot 10^{4}$ & 0.11 & 1.26 \\
\hline 8 & 0 & 1 & 0 & 0 & 1 & 2 & 1 & $15.9 \cdot 10^{4}$ & $-1.3 \cdot 10^{4}$ & $-8 \cdot 10^{4}$ & 0.03 & 0.36 \\
\hline 9 & 1 & 1 & 0 & 0 & 0 & 2 & 0 & $4.8 \cdot 10^{4}$ & $2.3 \cdot 10^{4}$ & $-6.3 \cdot 10^{4}$ & 0.02 & 0.31 \\
\hline 10 & 0 & 1 & 1 & 0 & 0 & 2 & 1 & $4.3 \cdot 10^{4}$ & & & & \\
\hline 11 & 0 & 0 & 1 & 1 & 0 & 2 & 1 & $4.2 \cdot 10^{4}$ & $0.53 \cdot 10^{4}$ & $3 \cdot 10^{4}$ & 0.09 & 1.02 \\
\hline 12 & 1 & 1 & 0 & 0 & 0 & 2 & 1 & $0.23 \cdot 10^{4}$ & $1.7 \cdot 10^{4}$ & & 0.03 & 0.19 \\
\hline 13 & 0 & 1 & 0 & 0 & 0 & 1 & 1 & $12.6 \cdot 10^{4}$ & $4 \cdot 10^{4}$ & $-0.6 \cdot 10^{4}$ & 0.14 & 0.90 \\
\hline 14 & 0 & 1 & 0 & 0 & 0 & 1 & 0 & $5.4 \cdot 10^{4}$ & $2.9 \cdot 10^{4}$ & $1.9 \cdot 10^{4}$ & 0.02 & 0.31 \\
\hline 15 & 1 & 0 & 0 & 0 & 0 & 1 & 0 & $1.3 \cdot 10^{4}$ & $1.2 \cdot 10^{4}$ & $3 \cdot 10^{4}$ & 0.11 & 0.90 \\
\hline 16 & () & 1 & 0 & 0 & 0 & 1 & 1 & $0.15 \cdot 10^{4}$ & $1.6 \cdot 10^{4}$ & $1.6 \cdot 10^{4}$ & 0.25 & 0.90 \\
\hline 17 & 0 & 0 & 0 & 0 & 0 & 0 & 1 & $14 \cdot 10^{4}$ & $-0.51 \cdot 10^{4}$ & $2 \cdot 10^{4}$ & 0.05 & 0.50 \\
\hline 18 & 0 & 0 & 0 & 0 & 0 & 0 & 1 & $9.3 \cdot 10^{4}$ & $0.36 \cdot 10^{4}$ & $3.3 \cdot 10^{4}$ & 0.13 & 1.05 \\
\hline 19 & 0 & 0 & 0 & 0 & 0 & 0 & 1 & $9.2 \cdot 10^{4}$ & $8.2 \cdot 10^{4}$ & $-0.2 \cdot 10^{4}$ & 0.03 & 0.21 \\
\hline 20 & 0 & 0 & 0 & 0 & 0 & 0 & 1 & $6 \cdot 10^{4}$ & $0.9 \cdot 10^{4}$ & $0.5 \cdot 10^{4}$ & 0.08 & 0.96 \\
\hline 21 & 0 & 0 & 0 & 0 & 0 & 0 & 1 & $5.5 \cdot 10^{4}$ & $0.38 \cdot 10^{4}$ & $1.3 \cdot 10^{4}$ & 0.07 & 1.09 \\
\hline 22 & 0 & 0 & 0 & 0 & 0 & 0 & 1 & $2.5 \cdot 10^{4}$ & $4.5 \cdot 10^{4}$ & $4.7 \cdot 10^{4}$ & 0.03 & 0.85 \\
\hline 23 & 0 & 0 & 0 & 0 & 0 & 0 & 0 & $1.5 \cdot 10^{4}$ & $3.9 \cdot 10^{4}$ & $3.1 \cdot 10^{4}$ & 0.09 & 0.90 \\
\hline 24 & 0 & () & 0 & 0 & 0 & 0 & 0 & $1.2 \cdot 10^{4}$ & $2.7 \cdot 10^{4}$ & $-0.18 \cdot 10^{4}$ & 0.03 & 0.29 \\
\hline 25 & 0 & () & 0 & 0 & 0 & 0 & 1 & $-1 \cdot 10^{4}$ & $0.41 \cdot 10^{4}$ & $0.6 \cdot 10^{4}$ & 0.14 & 0.79 \\
\hline 26 & 0 & 0 & 0 & 0 & 0 & 0 & 1 & $-1.5 \cdot 10^{4}$ & $1.3 \cdot 10^{4}$ & $4.6 \cdot 10^{4}$ & 0.07 & 0.60 \\
\hline 27 & 0 & 0 & 0 & 0 & 0 & 0 & 0 & $-3.1 \cdot 10^{4}$ & $1.9 \cdot 10^{4}$ & $-1.7 \cdot 10^{4}$ & 0.12 & 0.79 \\
\hline 28 & 0 & 0 & 0 & 0 & 0 & 0 & 0 & $-3.6 \cdot 10^{4}$ & $1 \cdot 10^{4}$ & $-1.1 \cdot 10^{4}$ & 0.08 & 1.35 \\
\hline
\end{tabular}

$\mathrm{E}_{\mathrm{B}}(r=0.09)$, and the inverse time constants $\mathrm{a}(r=0.08)$ and $b(r=0.11)$ did not have such a correlation $(P>0.10)$.

There was no difference between parameters whether the balloon was in the aganglionic area or above (Table I) $(P>0.05)$.

\section{DISCUSSION}

This study demonstrates that among the viscoelastic properties of the rectal wall, the "static" elastic constant $\mathrm{E}_{x}$ is significantly larger in patients with Hirschsprung's disease than in control subjects. This would indicate that the disease tends to stiffen the bowel. Moreover, a relationship exists between the increased stiffness expressed by the constant $\mathrm{E}_{\infty}$ and the clinical parameters that determine the severity of the disease. The exponential coefficients $a$ and $b$ are also significantly different in control subjects and in patients
TABLE II

Statistical Comparison between Viscoelastic Properties of the Rectal Wall of Normal Children and Children with Hirschsprung's Disease

\begin{tabular}{|c|c|c|c|}
\hline & Normal subjects & $\begin{array}{l}\text { Patients with } \\
\text { Hirschsprung's } \\
\text { disease }\end{array}$ & $P$ \\
\hline $\mathrm{E}^{x}$, dyne/cm & $\begin{aligned} \text { Mean } & =11.4 \times 10^{3} \\
\mathrm{SE} & =4.8 \times 10^{3}\end{aligned}$ & $\begin{aligned} \text { Mean } & =95.8 \times 10^{3} \\
S E & =23 \times 10^{3}\end{aligned}$ & $<0.001$ \\
\hline $\mathrm{E}_{\mathrm{A}}$, dyne/cm & $\begin{aligned} \text { Mean } & =16.7 \times 10^{3} \\
S E & =2.7 \times 10^{3}\end{aligned}$ & $\begin{aligned} \text { Mean } & =22 \times 10^{3} \\
\mathrm{SE} & =7.3 \times 10^{3}\end{aligned}$ & $>0.30$ \\
\hline$E_{B}$, dyne/cm & $\begin{aligned} \text { Mean } & =11.25 \times 10^{3} \\
\mathrm{SE} & =2.1 \times 10^{3}\end{aligned}$ & $\begin{aligned} \text { Mean } & =22.9 \times 10^{3} \\
\mathrm{SE} & =21 \times 10^{3}\end{aligned}$ & $>0.05$ \\
\hline $\mathbf{a} / \mathbf{s}$ & $\begin{aligned} \text { Mean } & =0.14 \\
\mathrm{SE} & =0.01\end{aligned}$ & $\begin{aligned} \text { Mean } & =0.09 \\
\mathrm{SE} & =0.01\end{aligned}$ & $<0.001$ \\
\hline $\mathrm{b} / \mathrm{s}$ & $\begin{aligned} \text { Mean } & =1.27 \\
\mathrm{SE} & =0.05\end{aligned}$ & $\begin{aligned} \text { Mean } & =0.75 \\
\mathrm{SE} & =0.05\end{aligned}$ & $<0.001$ \\
\hline
\end{tabular}


with Hirschsprung's disease. In the patients, the wall tension caused by sudden bowel distension decays more slowly than in the control subjects. A relationship between these parameters, which reflect the viscous properties of the rectal wall, and the severity of the disease, however, could not be established.

Most studies of rheological properties of visceral walls have been done in vitro without practical application to disease (10-15). A purpose of this study was to present the rheological modelization as a method able to describe a normal biomechanical function, and to analyze it in a few elementary parameters. Exhaustive description of pathological alterations of this function may then be done by comparing each parameter with the values determined in a group of normal subjects. This method was applied here by studying the adaptation of the rectal wall to a sudden distension in Hirschsprung's disease. In in vitro studies, the smooth muscle has a greater viscosity when contracted than when relaxed (16). This is in agreement with our findings in this study. Rectal accomodation to distension has been demonstrated before in intact human subjects (17), but the technique was only anecdotally applied to disease, and data were not quantified beyond a simple recording pressure. On the other hand, urinary bladders with fibrosis have a high elastic modulus and a prolonged duration of relaxation (18).

This study was also done to try to find an explanation for the discrepancy found in several cases between severity of disease and length of aganglionic segment. There was no relationship betwee the elastic modulus and the position of the distending balloon with regard to the aganglionic area. This means that marked symptoms may be given by a short aganglionic segment with a high elastic modulus and that total Hirschsprung's disease with a low elastic modulus may give very few symptoms. The physiopathology of the decreased elasticity is not known. It is not possible to rule out at this stage the role of connective tissue content that would affect the viscoelastic properties of the rectal wall and, of course, contractile activity even in the resting muscle (19). The decreased elasticity could be a consequence of Cannon's law, where denervated smooth muscle cells are hyperexcitable. However, in some of our cases, the balloon was clearly above the aganglionic segment and the elasticity was decreased. This means essentially that it is not sufficient to simply state that ganglionic cells are absent and to establish the extent of the aganglionosis to obtain a diagnosis of, and, a prognosis for Hirschsprung's disease. Presence of ganglion cells does not necessarily imply normal functions of these cells. It is probably necessary to also establish the presence, localization, and amount of neurotransmitters. The number of acetyl cholinesterase positive nerves (20) and the extent of sacral parasympathetic innervation of the circular muscle of the aganglionic colon (21) are other elements to consider. Moreover, results of pathological examinations are simply given in terms of "presence" or "absence" of neurones: an intermediate zone between normal proximal area and aganglionic distal area should be considered with a "decrease" in number of innervated cells. The morphological evaluation of this zone poses serious problems, but its functional importance may be appreciated by a quantification of its rheological disorders.

In practical terms, results of this study mean that to diagnose and assess the severity of Hirschsprung's disease, it is sufficient to distend the rectum, determine the elastic coefficient $E_{\infty}$ of the rectal wall, and record the absence of a rectoanal inhibitory reflex.

\section{ACKNOWLEDGMENTS}

The research for this paper was partly supported by grants from the Institut National de la Santé et de la Recherche Médicale, France, CRL no. 77.2.1857; Medical Research Council of Canada, MT-3511; La sous-commission francoquébécoise pour les sciences de la santé.

\section{REFERENCES}

1. Ehrenpreis, T. 1966. Some newer aspects on Hirschsprung's disease and allied disorders. J. Pediatr. Surg. 1: 329.

2. Bodian, M., D. Stephens, and B. Ward. 1949. Hirschsprung's disease and idiopathic megacolon. Lancet. I: 6.

3. Stone, W. D., T. R. Hendrix, and M. M. Schuster. 1965. Aganglionosis of the entire colon in an adolescent. Gastroenterology. 48: 636 .

4. Arhan, P., C. Faverdin, and B. Persoz. 1976. Relationship between viscoelastic properties of the rectum and anal pressure in man. J. Appl. Physiol. 41: 677.

5. Tobon, F., N. C. R. W. Reid, J. L. Talbert, and M. M. Schuster. 1968. Nonsurgical test for the diagnosis of Hirschsprung's disease. N. Engl. J. Med. 278: 188.

6. Ustach, T. J., F. Tobon, and M. M. Schuster. 1969. Simplified method for diagnosis of Hirschsprung's disease. Arch. Dis. Child. 44: 694.

7. Arhan, P., C. Faverdin, and J. Thouvenot. 1972. Anorectal mortility in sick children. Scand. J. Gastroenterol. 7: 309.

8. Arhan, P., C. Faverdin, and G. Devroede. 1976. Manometric assessment of continence after surgery for imperforate anus. J. Pediatr. Surg. 2: 157.

9. Schwartz, D. 1975. Méthodes statistiqus á l'usage des médecins et biologistes. Flammarion Médecine Sciences, Paris. 256.

10. Bawa, P., A. Mannard, and R. B. Stein. 1976. Predictions and experimental tests of a viscoelastic muscle model using elastic and inertial loads. Biol. Cybern. 22: 139.

11. Bawa, P., A. Mannard, and R. B. Stein. 1976. Effects of elastic loads on the contraction of cat muscles. Biol. Cybern. 22: 129.

12. Cohen, R. E., C. J. Hooley, and N. G. McCrum. 1976. Viscoelastic creep of collagenous tissue. J. Biomech. 9: 175.

13. Coolsaet, B. L. R. A., R. Van Mastrigt, and W. A. 
Van Duyl. 1976. Viscoelastic properties of bladder wall strips at constant elongation. Invest. Urol. 13: 435.

14. Glantz, S. A. 1974. A constitutive equation for the passive properties of muscle. J. Biomech. 7: 137.

15. Lestienne, F., and E. Pertuzon. 1974. Détermination in-situ, de la viscoélasticité du muscle humain inactivé. Eur. J. Appl. Physiol. Occup. Physiol. 32: 159.

16. Apter, J. T. 1966. Correlation of viscoelastic properties of large arteries with microscopic structure. III. Circumferential viscous and elastic constants measured in vitro. Circ. Res. 19: 104-121.

17. Lium, R. 1939. Observations on the etiology of ulcerative colitis. IV. The rectometrogram and the rectal reactions of 8 normal subjects and one patient with ulcerative colitis before and after spinal anesthesia. Am. J. Med. Soc. 197: 841 .
18. Kondo, A., and J. Susset. 1972. Viscoelastic properties of a bladder. Invest. Urol. 10: 459.

19. Siegman, M. J., T. M. Butler, and S. U. Mooers. 1976. Calcium-dependent resistance to stretch and stress relaxation in resting smooth muscles. Am. J. Physiol. 231: 1501 1508.

20. Garrett, J. R., E. R. Howard, and H. H. Nixon. 1969. Autonomic nerves in rectum and colon in Hirschsprung's disease. A cholinesterase and catecholamine histochemical study. Arch. Dis. Childh. 44: 406.

21. Meier-Ruge, W., O. Hunziker, and H. J. Tobler. 1972. The pathophysiology of aganglionosis of the entire colon (Zuelzer-Wilson syndrome). Morphometric investigations of the extent of sacral parasympathetic innervation of the circular muscles of the aganglionic colon. Beitz. Path. Bd. 147: 228. 